\title{
Morphological and morphometrical studies of the human foetal lung
}

\author{
Rajeev Mukhia', Dil Islam Mansur', Sidharth Timsina ${ }^{3}$, Taneja BK \\ ${ }^{1}$ Assistant Professor, Department of Anatomy, Manipal College of Medical Sciences, Pokhara, Nepal, ${ }^{2}$ Associate \\ professor, Department of Anatomy, Kathmandu University School of Medical Sciences, Dhulikhel, Nepal, ${ }^{3}$ Assistant \\ Professor, Department of Forensic Medicine, Manipal College of Medical Sciences. Pokhara, Nepal, ${ }^{4}$ Professor, \\ Department of Obstetrics and Gynaecology, Manipal Teaching Hospital, Phulbari, Pokhara, Nepal
}

Background: Foetal lung is one of the organs of interest for researchers since a long time. Though, detailed study about adult lung is there in the literature but lungs at different stages in foetal period is less available. Aims and Objective: To find out the morphological and morphometrical features of the foetal lung in different gestational weeks. Materials and Methods: After ethical approval the study was carried out on 66 human foetal lungs aged between $16^{\text {th }}$ to $40^{\text {th }}$ gestational weeks in the Department of Anatomy, Manipal College of Medical Sciences. After the dissection of foetuses, the lungs were removed out and the presence of fissures and lobes for both lungs were noted. Weights of both lungs were calibrated by digital weighing machine. Dimensions of foetal lungs were recorded by vernier calliper. All the data were represented as mean then analyzed with MS excel 2007 software and represented graphically. Results: In the normally developing foetuses the dimensions of both lung increases with increase in gestational age with more or less difference between the dimension of right and left lung. There was number of variations seen in the fissures and lobes of the lungs. Conclusion: The fissures and lobes are needed for locating bronchopulmonary segments hence, knowledge of their position is necessary both anatomically as well as clinically for planning lobectomies and surgical resections.

Access this article online

Website:

http://nepjol.info/index.php/AJMS DOI: 10.3126/ajms.v10i5.22136 E-ISSN: 2091-0576 P-ISSN: $2467-9100$

Key words: Foetal lung; Dimension; Variations; Fissures; Lobes

\section{INTRODUCTION}

The lungs are located on either side of the heart and occupy the lateral thoracic cavity. Each lung is free in its pleural cavity, except at the hilum and pulmonary ligament. When normal lungs removed from the thorax, it is highly elastic and spongy can float in water because of the air within its alveoli. Its surface is smooth and shiny. ${ }^{1}$ The right lung is heavier than left lung. The lungs are heavier in male as compared to female. ${ }^{2}$ The development of lung begins at fourth weeks of embryonic life from a respiratory bud and continues into postnatal life till the maturation is complete. ${ }^{3}$

Lungs are divided into lobes by the oblique and the transverse fissures. The oblique fissure cuts the vertebral border of both the lungs at the level of $4^{\text {th }}$ or $5^{\text {th }}$ thoracic spine. Horizontal fissure, seen only in the right lung begins laterally at the oblique fissure and runs almost transversely across the costal surface to the anterior margin and around this margin back to the hilum. ${ }^{4}$

The fissures facilitate the movement of the lobes in relation to one another, which accommodates the greater distension and movement of the lower lobes during respiration. Thus, they help in a more uniform expansion of the whole lung. Other than the normal anatomy, different variations in the fissure patterns are observed in the form of incomplete fissures where there is fusion of lung parenchyma between the lobes and absent fissures or accessory fissures of varying depth, delimiting anomalous lobes corresponding to normal broncho-pulmonary segments. ${ }^{5}$

There are lots of major and minor variations in lung anatomy, which may significantly affect the outcome of 
medical procedures related to patients suffering from lung disease. Since diagnostic imaging and surgical technique for lungs is rapidly evolving, variation in lung anatomy should also be updated, and kept up-to-date with these things. Hence the present study was done to study the morphological and morphometrical features on the development of foetal lung in different gestational weeks. Though, detailed morphological and morphometrical studies of the adult lung is available the studies of the human foetal lung still have a large scope for researchers.

\section{MATERIALS AND METHODS}

The present study was carried out on 66 human foetal lungs aged between $16^{\text {th }}$ to $40^{\text {th }}$ gestational weeks in the Department of Anatomy, Manipal College of Medical Sciences, Pokhara from July 2018 to July 2019. After ethical review from IRC and permission from the Department of Obstetrics and Gynaecology, the foetuses were collected in $10 \%$ formalin. The age of foetuses was calculated from the obstetrical history, crown rump length (CRL) and crown heel length (CHL). The dissection was done according to the "Cunningham's manual of practical anatomy $15^{\text {th }}$ edition and the lungs were removed. ${ }^{6}$ Only normal lungs (lungs with intact visceral pleura covering all over it except at hilum) were included in the study. Lungs with any anomaly or pathology or damaged lungs during removal were not included in the study.

Presence of oblique fissure, horizontal fissure, accessory fissure, absent fissure and numbers of lobes were noted. Weight of lungs was calibrated by weighing machine and dimensions like length of anterior border, posterior border and inferior border of both lungs were recorded by vernier calliper, thread and scale. All the data were represented as mean then analyzed with MS Excel 2007 software and represented graphically.

\section{RESULTS}

The present study was carried out 66 foetal lungs ranging from $16^{\text {th }}$ to $40^{\text {th }}$ weeks in the Department of Anatomy, of Manipal College of Medical Sciences. The dissection of foetuses and relation of lungs with others visceral structures is shown in figure 1. Variations in fissures and lobes in right and left foetal lung are shown in figure 2. Absence both oblique and horizontal fissures in right foetal lung and absence of oblique fissure in left foetal lung is shown in figure 3. The mean length of anterior border of right lung at $16-20$ g.w and $36-40$ g.w is $25.4 \mathrm{~mm}$ and $48.8 \mathrm{~mm}$ respectively. The mean length of anterior border of left lung at $16-20$ g.w and $36-40$ g.w is $26.8 \mathrm{~mm}$ and $52.2 \mathrm{~mm}$ respectively. The mean length of posterior border of right lung at 16-20 g.w and 36-40 g.w is $26.1 \mathrm{~mm}$

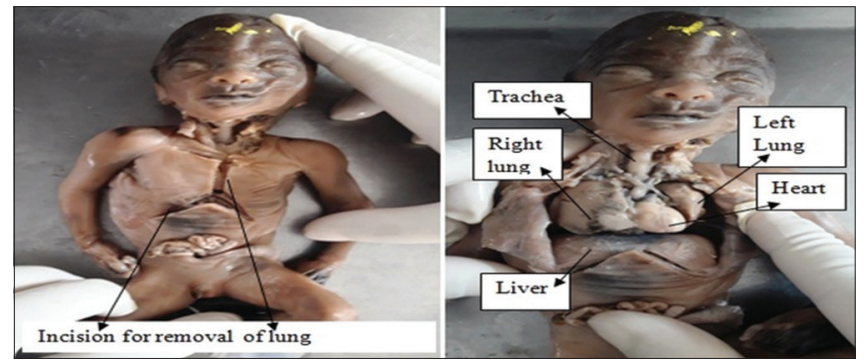

Figure 1: Dissection of foetuses and relation of lungs with others visceral structures

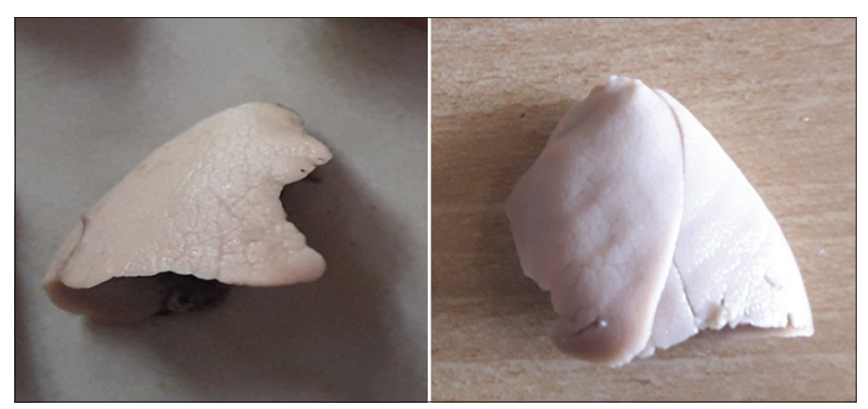

Figure 2: Variations in fissures and lobes in right and left foetal lung. In right lung there is only 1 fissure so 2 lobes and in left lung 2 fissures so 3 lobes

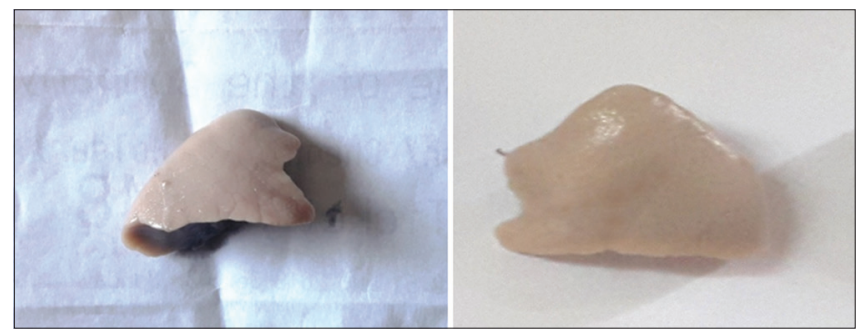

Figure 3: Absence of both oblique and horizontal fissures in right foetal lung and absence of oblique fissure in left foetal lung

and $49.6 \mathrm{~mm}$ respectively. The mean length of posterior border of left lung at $16-20$ g.w and $36-40$ g.w is $27.3 \mathrm{~mm}$ and $53.1 \mathrm{~mm}$ respectively. The mean length of inferior border of right lung at $16-20$ g.w and $36-40$ g.w is $54.2 \mathrm{~mm}$ and $160.2 \mathrm{~mm}$ respectively. The mean length of inferior border of left lung at $16-20$ g.w and $36-40$ g.w is $50.4 \mathrm{~mm}$ and $153.9 \mathrm{~mm}$ respectively. The results of mean length of anterior, posterior and inferior border of right and left lung at different gestational weeks are shown in Table 1 and figure 4. The mean weight of right lung at 16-20 g.w and 36$40 \mathrm{~g} . \mathrm{w}$ is $5.7 \mathrm{gm}$ and $25.7 \mathrm{gm}$ respectively. The mean weight of left lung at $16-20$ g.w and $36-40$ g.w is $5.5 \mathrm{gm}$ and $25.2 \mathrm{gm}$ respectively. The result of mean weight of right and left lung at different gestational weeks is shown in Table 1. Total 97 lobes were observed in right lung having 32 horizontal fissure, 32 oblique fissure and 8 accessory fissure and 67 lobes were observed in left lung having 32 oblique fissure, 2 horizontal fissure and 5 accessory fissure. The right and left lung shows $97.9 \%$ and $98.5 \%$ normal lobes respectively. 
The results of fissure parameters, number of fissures and lobes of both lungs is shown in Table 2 .

\section{DISCUSSION}

Numerous previous studies dealing with the development of the human lung in foetal period and variations in fissures and lobes mainly contain qualitative descriptions processes.
Thus, the present study deals with the quantitatively information of the foetal lungs, and also deals with the anomalous fissures and lobes along with their patterns, from early to late gestational weeks of developing foetuses.

Meenakshi et al. found incomplete oblique fissures in 36.6\% and $46.6 \%$ of the right and left sided lungs respectively. ${ }^{7}$ Incomplete horizontal fissure was in $63.3 \%$ right lungs.

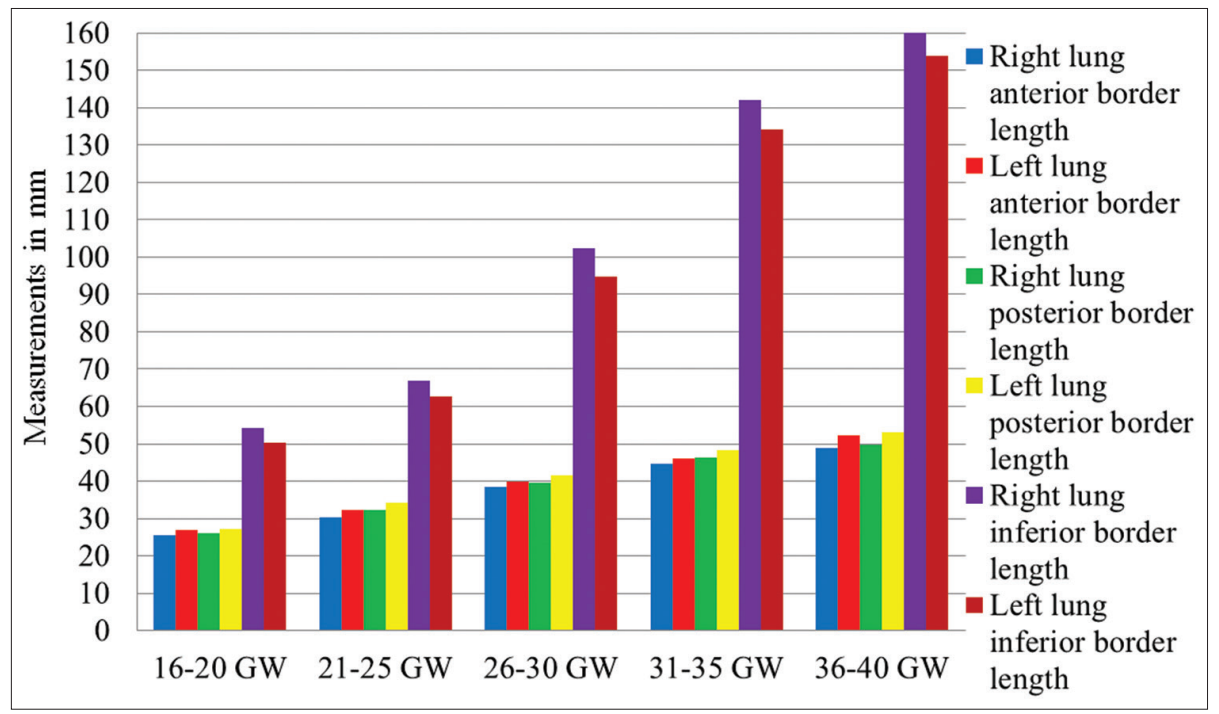

Figure 4: Mean length of anterior, posterior and inferior border of right and left lung in $\mathrm{mm}$ at different gestational weeks (GW)

\begin{tabular}{|c|c|c|c|c|c|c|c|c|c|}
\hline \multirow{2}{*}{$\begin{array}{l}\text { Gestational } \\
\text { Weeks } \\
\text { (GW) }\end{array}$} & \multirow[t]{2}{*}{$\begin{array}{c}\text { Number of } \\
\text { foetal lungs }\end{array}$} & \multicolumn{2}{|c|}{$\begin{array}{l}\text { Length of anterior } \\
\text { border in } \mathrm{mm}\end{array}$} & \multicolumn{2}{|c|}{$\begin{array}{l}\text { Length of posterior } \\
\text { border in } \mathrm{mm}\end{array}$} & \multicolumn{2}{|c|}{$\begin{array}{l}\text { Length of inferior } \\
\text { border in } \mathrm{mm}\end{array}$} & \multicolumn{2}{|c|}{$\begin{array}{c}\text { Weight of lungs in } \\
\text { gram }\end{array}$} \\
\hline & & $\begin{array}{l}\text { Right } \\
\text { lung }\end{array}$ & $\begin{array}{l}\text { Left } \\
\text { lung }\end{array}$ & $\begin{array}{l}\text { Right } \\
\text { lung }\end{array}$ & $\begin{array}{l}\text { Left } \\
\text { lung }\end{array}$ & $\begin{array}{l}\text { Right } \\
\text { lung }\end{array}$ & $\begin{array}{l}\text { Left } \\
\text { lung }\end{array}$ & $\begin{array}{l}\text { Right } \\
\text { lung }\end{array}$ & $\begin{array}{l}\text { Left } \\
\text { lung }\end{array}$ \\
\hline $16-20$ & 16 & 25.4 & 26.8 & 26.1 & 27.3 & 54.2 & 50.4 & 5.7 & 5.5 \\
\hline $21-25$ & 14 & 30.2 & 32.4 & 32.2 & 34.2 & 66.8 & 62.6 & 15.3 & 14.7 \\
\hline $26-30$ & 16 & 38.4 & 39.8 & 39.7 & 41.6 & 102.3 & 94.7 & 19.5 & 18.9 \\
\hline $31-35$ & 8 & 44.6 & 46.2 & 46.4 & 48.2 & 142.1 & 134.2 & 22.8 & 22.5 \\
\hline $36-40$ & 12 & 48.8 & 52.2 & 49.6 & 53.1 & 160.2 & 153.9 & 25.7 & 25.2 \\
\hline
\end{tabular}

Table 2. Showing fissure parameters, number of fissures and lobes of both lungs

\begin{tabular}{|c|c|c|c|c|}
\hline Lungs & No. of lungs & Fissure parameters & No. of fissures & No. of lobes \\
\hline \multirow[t]{9}{*}{ Right lung } & 33 & Horizontal & & 97 \\
\hline & & Incomplete & 13 & \\
\hline & & Absent & 1 & \\
\hline & & Normal & 19 & \\
\hline & & Oblique & & \\
\hline & & Incomplete & 10 & \\
\hline & & Absent & 1 & \\
\hline & & Normal & 22 & \\
\hline & & Accessory & 8 & \\
\hline \multirow[t]{6}{*}{ Left lung } & 33 & Oblique & & 67 \\
\hline & & Incomplete & 25 & \\
\hline & & Absent & 1 & \\
\hline & & Normal & 7 & \\
\hline & & Horizontal & 2 & \\
\hline & & Accessory & 5 & \\
\hline
\end{tabular}


Lukose et al. found incomplete and absent horizontal fissure in $21 \%$ and $10.5 \%$ respectively. ${ }^{8}$ Incomplete oblique fissure was present in $21 \%$ of left-sided lungs. According to Bhimai Devi et al. incomplete horizontal and oblique fissures were seen in $18 \%$ and $9 \%$ of the total right lungs studied. ${ }^{9}$ Aziz et al. in their CT scan (HRCT) study, observed incomplete right oblique fissure in $48 \%$ of cases and incomplete left oblique fissure in $43 \%$ of cases. Incomplete horizontal fissure was observed in 63\% right lungs. ${ }^{10}$ In the present study, 19 lungs showed normal pattern of horizontal fissure, incomplete horizontal fissure was observed in 13 right lungs and 1 lung showed absent horizontal fissure. Incomplete oblique fissure was observed in 10 right lung specimen and 1 lung showed absent oblique fissure. 7 lungs of left side showed normal pattern of oblique fissure. Incomplete oblique fissure was observed in 25 left lung specimen, 1 lung showed absent oblique fissure where as 2 left lung shows presence of horizontal fissure also. Nene AJ et al. observed the accessory fissure in $18 \%$ and $24 \%$ of lungs on right and left sides respectively. ${ }^{11}$ Godwin and Tarver observed accessory fissure in $40 \%$ of right lungs and $50 \%$ of left lung specimens. ${ }^{12}$ Berkmen et al. in their imaging study, found 18 accessory fissures. ${ }^{13}$ In the present study, accessory fissure was observed in 8 right lung and 5 left lung specimens.

No significant difference in the foetal lung dimensions between both sexes was corroborated by the authors except Gerards et al. who reported the foetal lung volumes were greater in males as compared with female by approximately $4.3 \%{ }^{14-17,18}$ The present study was done on human foetuses with irrespective of sex and is the main limitation of the study. In the present study the growth rate of right lung was found little faster than that of left lung throughout the gestational period. Others findings including growth of right and left lung reported by Gerards et al. is almost similar in conformity with the finding of the present study except for some findings in some weeks of gestation which may be deviated due to difference in sample size of study, genetic and environmental factors which may affects the foetal and lung development. ${ }^{18}$ To the best of our knowledge, this study has completely investigated the morphometric features of foetal lungs from early to late gestational age foetuses.

\section{CONCLUSION}

From the study we confirm that in the normally developing foetuses the dimensions of both lung increases with increase in gestational age with more or less difference between the dimension of right and left lung. There was number of variations seen in fissures and lobes in the present study. The fissures delimit the lobes and thus are needed for locating broncho-pulmonary segments hence, knowledge of their position is necessary both anatomically as well as clinically for planning lobectomies and surgical resections. Detailed knowledge of variations in fissures and lobes is also of interest to all medical professionals to exactly interpret radiographs, computed tomography scans, to diagnose, plan and modify a surgical procedure. This will help to reduce the morbidity and mortality associated with lung surgeries.

\section{ACKNOWLEDGEMENTS}

The author expresses special thanks to all the faculties and non-teaching staff members of Anatomy Department and Obstetrics and Gynaecology Department, MCOMS, Pokhara for their support.

\section{REFERENCES}

1. Standring S. Gray's anatomy: The anatomical basis of clinical practice. $40^{\text {th }}$ ed. Edinburgh: Churchill Livingstone/Elsevier; 2008; 1428-1430.

2. Thurlbeck WM. Postnatal human lung growth. Thorax 1982; 37(8):564-571.

3. Keith $\mathrm{L}$ Moore. The Developing Human Clinically Oriented Embryology: 10 ${ }^{\text {th }}$ ed. Philadelphia/Elsevier, 2016; 196-207.

4. Rosse C, Gaddum-Rosse P. Hollinshed's Textbook of Anatomy. $5^{\text {th }}$ ed. Philadelphia: Lipincott-Raven; 1997: 441-61.

5. Mossman Boyd and Hamilton. Development of respiratory system. In: William James Hamilton, James Dixon Boyd, Harland Winfield Mossman. Human Embryology (Prenatal Development of Formation and Function). $3^{\text {rd }}$ ed. Cambridge: Heffer, 1964; 230-234.

6. Romanes GJ. Cunningham's manual of practical anatomy $15^{\text {th }}$ ed. Vol 2 Thorax and Abdomen, Oxford medica publication; 1986; 34-42.

7. Meenakshi S, Manjunath KY and Balasubramanyam V. Morphological variations of lung fissures and lobes. Ind J Chest Dis Allied Sci 2004; 46(3):179-182.

8. Lukose R, Paul S and Sunitha V. Morphology of lungs: variations in lobes and fissures. Biomed 1999; 19(3):227-232.

9. Bhimai ND, Rao BN and Sunitha V. Morphological variations of lung- a cadaveric study in north coastal Andhra Pradesh. Int J Biol Med Res 2011; 2(4):1149-1152.

10. Aziz A, Azshizawa K, Nagaoki K and Hayashi K. High resolution CT anatomy of the pulmonary fissures. J Thorac Imaging 2004; 19(3):186-191.

11. Nene AJ, Gajendra KS and Sarma MVR. Lung lobes and fissures: a morphological study. Anatomy 2011; 5:30-38.

12. Godwin JD and Tarver RD. Accessory fissures of the lung. AJR Am J Roentgenol 1985; 144(1): 39-47.

13. Berkmen T, Berkmen YM and Austin JH. Accessory fissures of the upper lobe of the left lung: CT and plain film appearance. Am J Roentgenol 1994; 162(6):1287-1293.

14. Britto IS and de Silva Bussamral LC. Fetal lung volume: comparison by 2D- and 3D-sonography in normal foetuses. Archives of Gynecology and Obstetrics 2009; 280(3):363-368.

15. Kasprian G, Balassy C, Brugger PC and Prayer D. MRI of normal and pathological fetal lung development. European Journal of Radiology 2006; 57(2):261-270. 
16. Chang $\mathrm{CH}, \mathrm{Yu} \mathrm{CH}$, Chang $\mathrm{FM}$, Ko $\mathrm{HC}$ and Chen $\mathrm{HY}$. Volumetric assessment of normal fetal lungs using threedimensional ultrasound. Ultrasound in Medicine and Biology 2003;29(7):935-942.

17. Bahmaie A, Hughes SW and Clark T. Serial fetal lung volume measurement using three-dimensional ultrasound. Ultrasound in Obstetrics \& Gynaecology 2000; 16(2):154-158.

18. Gerards FA, Engels MAJ, Twisk JWR and Van Vugt JMG. Normal fetal lung volume measured with three-dimensional ultrasound. Ultrasound in Obstetrics \& Gynaecology 2006; 27(2):134-144.

Authors Contribution:

RM and DIM-Concept and designed the study; RM- Collected the foetuse, analysed the data, interpreted the findings and prepared the manuscript;

RM, DIM, ST and BKT- Reviewed the manuscript.

Work attributed to:

Study was conducted in the Department of Anatomy, Manipal College of Medical Sciences, Manipal Teaching Hospital, Pokhara, Nepal.

Orcid ID:

Dr. Rajeev Mukhia- (1) https://orcid.org/0000-0003-4604-3789

Source of Support: Nil, Conflict of Interest: The authors hereby declare that they have no conflict of interests. 